\title{
Challenging the Other: Exploring the Role of Opponent Gender in Digital Game Competition for Female Players
}

\author{
Lotte Vermeulen, MA, Elena Núñez Castellar, PhD, and Jan Van Looy, PhD
}

\begin{abstract}
The present study investigated the effect of opponent gender on the game experience of female players. Concretely, it looked into skill perception and player emotions of women in same gender and cross-gender game competition. We set up a $2 \times 2 \times 2$ (male vs. female opponent $\times$ low vs. high competitive women $\times$ lost vs. won game) experimental design in which women were instructed to play against a proclaimed male and female competitor. Unknowingly, however, participants played against an AI, which was configured to produce a winning and a losing condition for each opponent by manipulating difficulty. Results indicated that opponent gender only had an effect on perceived stress, which was higher with male opponents. Moreover, players evaluated their own gaming skills as lower and the skills of presumed male opponents as higher when they thought they were playing against men. Importantly, our results also showed that the above described pattern for self-perceived skills and perceived opponent skills was modulated by trait competitiveness with a larger effect size for low competitive women. Overall, this study illustrates that gender dynamics affect the play experience of women in cross-gender gaming competition. Implications and suggestions for future research are discussed.
\end{abstract}

\section{Introduction}

$\mathbf{I}^{\mathrm{r}}$ $\mathrm{N}$ THE PAST DECADES, digital gaming has become a mainstream pastime, playing an ever more important role in the lives of a growing variety of both men and women. ${ }^{1}$ The growth of the female gamer segment has been impeded, however, by the persistent view that games are predominantly "male territory.", 2 Scholarly research has tried to explain this gender bias by raising questions about popular themes, ${ }^{5,6}$ female avatar representation, ${ }^{7,8}$ and gaming access for women. ${ }^{9,10}$ Related to this, a fourth possible explanation for the limited female presence in the gaming space is reluctance to engage in cross-gender competition due to cultural norms of gender division. ${ }^{11}$

The social cognitive theory (SCT) of gender development and differentiation ${ }^{12}$ explains gender-linked conduct in terms of a triadic reciprocal causation in which interactions occur between environmental forces, personal factors, and behavior. Much of what is acquired in this dynamic process takes place through social modeling referring to observational learning of gender-linked behavior. ${ }^{12,13}$ Next to parents and peers, media hold a central position in providing symbolic models of gendered roles and conduct. ${ }^{12,14}$ It is argued that digital games in particular tend to promote traditional gender ideals, for instance, by underrepresenting women and diffusing sexualized images. ${ }^{7,8,15}$ Besides providing role models, gaming itself concerns a gendered leisure activity. Unlike many other media, such as television or radio, playing games is a behavior that is typically associated with males. ${ }^{16-18}$ This is not surprising, as history shows how men were continuously favored by the game industry and thus steadily grew as its core audience. ${ }^{19,20}$ Furthermore, female players, especially those of games perceived as masculine, are reported to encounter harassments as a result of their mismatch with socially acceptable feminine roles. ${ }^{21-24}$ This becomes particularly apparent when women are overtly competing against male players as "cross-gender challenges call into question the whole social order.",11(p476) This is further corroborated by research into tournament entry, showing that women are more reluctant than men to enter cross-gender competitive environments. ${ }^{25,26}$ In other words, it seems that gender dynamics thwart competition between men and women in game contexts. Whereas previous research showed that females experience more aggressive thoughts when playing against males, ${ }^{27}$ no empirical study has looked into the effects of cross-gender competition on the broader game experience of female players. The present article aims to fill this gap and thus further our understanding

Department of Communication Sciences, iMinds-MICT-Ghent University, Ghent, Belgium. 
of the role of gender differences in game play. Concretely, we propose the following research question:

\section{RQ: How does opponent gender affect the game experience of female players?}

Beliefs about one's capabilities play a major role in competition. According to SCT, people's expected outcomes function as a motivating source to execute certain behavior. To reach certain outcomes successfully, behavior should be supported by a sense of self-efficacy, that is, one's perceived capability and skills to produce an attainment. ${ }^{28}$ However, self-efficacy is susceptible to gender stereotyping, as it diminishes judgments about personal abilities. ${ }^{12}$ The theory of stereotype threat ${ }^{29}$ explains the mechanism underlying this process by stating that the psychological threat to confirm a negative stereotype about one's social category undermines performance expectations. ${ }^{29-32}$ This identity threat is most likely to occur in competitive environments ${ }^{33,34}$ such as in mediated contests. ${ }^{35}$ Given that female gamers take a marginalized position in a male dominated environment, ${ }^{16}$ this may lead to lower self-confidence when competing against male opponents. Low self-efficacy can function as a barrier to competition, motivating women to play solitarily, ${ }^{36}$ adopt more acceptable gaming roles such as caregiver, ${ }^{37}$ or even avoid playing games altogether. ${ }^{11}$

According to stereotype threat theory, performing in a domain in which one is stereotyped evokes negative emotional or arousal-based reactions. ${ }^{38-41}$ Positive emotions are crucial in the determination of future behavior, ${ }^{42}$ however, for example for playing games. Poels et al., ${ }^{43}$ for instance, found that positive emotions such as pleasure and arousal are predictive for future play. Moreover, competition has been found to influence emotional responses to digital games. ${ }^{27,44}$ Given that social competition involves social evaluative elements, ${ }^{44}$ it is plausible that "every evaluation...leads to an emotional state (enjoyment, stress, frustration) that differs in accordance to how the 'status quo' is perceived.',45(p4) Thus, if female players experience stereotype threat, cross-gender gaming competition may evoke lower positive emotional responses than same gender competition. Hence, we propose the following hypotheses:

H1: In cross-gender competition, female players will experience more challenge and estimate their skill as lower than in same gender competition.

H2: In cross-gender competition, female players will experience higher arousal and negative affect than in same gender competition.

Trait competitiveness can serve as a buffer against the negative effects of threatening situations. ${ }^{46}$ It could be, for example, that high competitive people reappraise the situation as a challenge, while low competitive people are more concerned with the threat. ${ }^{29,46}$ This is in line with research findings regarding sports performance, which demonstrate that athletes with high competitive anxiety have a disposition to worry more about situational threats. ${ }^{47-49}$ Thus, it is possible that competition-oriented women are less prone to gender dynamics in cross-gender tournaments. The current study looks into this claim and explores whether competitiveness has a moderating effect on emotions and perceived skill in cross-gender game play.

\section{Method}

\section{Participants}

Participants were recruited via e-mail and flyers distributed on the University campus (Ghent University, Ghent, Belgium). Forty-nine female college students participated in the experiment. Given that the subjects had to win and lose against a proclaimed male and female opponent, three participants were excluded due to a failed winning condition, and seven were removed because of suspicions regarding the experimental setup. Thirty-nine participants were retained $\left(M_{\mathrm{age}}=24.33\right.$, $S D=4.92, \min =20, \max =49)$, of whom $13 \%$ indicated that they never played games, $33 \%$ played at least once a year, $28 \%$ played monthly, $13 \%$ played weekly, and $13 \%$ played daily.

\section{Design}

A $2 \times 2 \times 2$ (competitiveness: high vs. low $\times$ opponent: male vs. female $\times$ outcome: win vs. lose) mixed analysis of variance (ANOVA) design was used to examine the effect of cross-gender competition in game play. The betweensubjects factor was trait competitiveness and the withinsubjects factors were opponent gender and game outcome.

\section{Measures}

Competitiveness. We measured trait competitiveness to investigate its moderating effect on emotions and perceived skill using the Revised Competiveness Index, a structured personality instrument consisting of 14 five-point Likert items. ${ }^{50}$

Subjective measures. To test whether emotional responses were modulated by the cross-gender manipulation, participants filled out the 9-point Self-Assessment Manikin (SAM) of Lang ${ }^{51}$ after each play session. This visual selfreport scale directly measures people's affective reaction to a certain stimulus in terms of pleasure, arousal, and dominance. ${ }^{52}$ Additionally, similar to Mastro et al., ${ }^{53}$ subjective levels of stress and frustration were measured by two items ranging from $0=$ "not at all" to $10=$ "extremely." To assess skill and perceived challenge, 4-item Likert scales from Novak et al. ${ }^{54}$ were used, which ranged from $1=$ "strongly disagree" to $9=$ "strongly agree." Moreover, participants rated their opponents' skills on a 10-point scale from $0=$ "very bad" to $10=$ "very good" after each session.

Objective measures. Objective performance, which was recorded using an automatic logging system built into the game, was measured with a total of three parameters of ingame behavior: playing time, player's score in losing condition, and the AI's score in the winning condition.

\section{Procedure}

We adapted a three-dimensional (seemingly) multiplayer version of the game Pong ${ }^{55}$ (see Fig. 1) in collaboration with GriN Multimedia. In contrast to previous studies on crossgender competition, ${ }^{27}$ we opted for a gender neutral and nonviolent game to exclude potential influence from stereotypical male-oriented themes. ${ }^{56}$

Participants were welcomed and introduced to a male and a female opponent before being escorted to a separate room. There they were asked to compete in four rounds of Pong, 


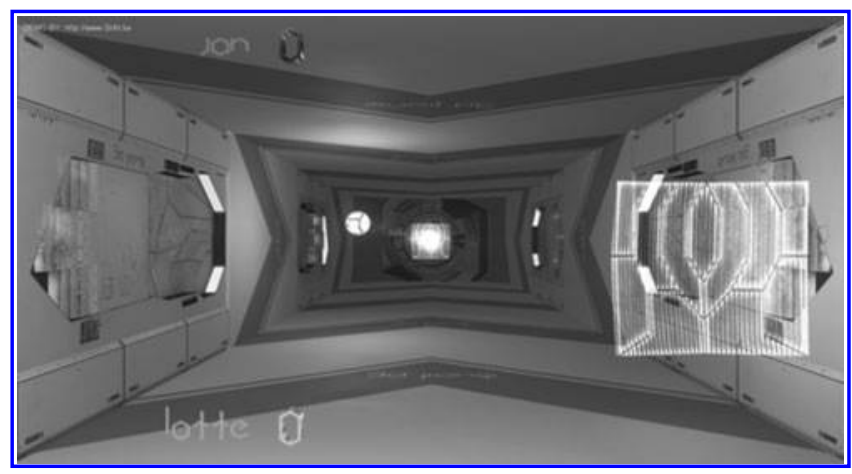

FIG. 1. Screenshot of the Pong game developed by GriN Multimedia.

two against each opponent. In reality, the opponents were confederates, and the test person played against an AI configured to produce a winning and a losing condition for each opponent by manipulating difficulty. Before each play session, a screen was shown with the name of the opponent for 15-30 seconds. Opponent order was randomized. As a manipulation check, we asked participants to recall the name of their opponent correctly after each play session. These answers were compared afterwards with the game's log files, which indicated that no participant had reported an incorrect name. After each session, participants had to fill out a questionnaire about their emotions while playing, their perceived skill, and game aesthetics (i.e., cover questions).

\section{Results}

\section{Scale validity}

The trait competitiveness scale had high reliability $(\alpha=0.87)$. The mean score for the total sample was 44.69 $(S D=7.82)$. Categorization of participants into low $(n=19)$ and high $(n=20)$ competitive women was based on a median split $(M d n=47$, range $=32)$. No significant differences were found between groups for gaming frequency, $t(37)=-1.29$, $p=0.204$, and expected chance of winning, $t(37)=1.30$, $p=0.200$.

\section{Descriptive statistics}

Table 1 reports the main descriptive statistics for the opponent gender conditions and the subjective dependent variables used in this study. Overall, Table 1 illustrates that game outcome was an important determinant for all dependent measures.

\section{Analysis}

SAM scale. Using the SAM scale, ${ }^{51}$ we looked into the self-reported player emotions of pleasure, arousal, and dominance. As shown in Table 2, there was no effect of opponent gender or trait competitiveness on these emotional responses. Game outcome, however, had an effect on pleasure, $F(1,37)=71.33, p<0.001, r=0.81$, and dominance, $F(1,37)=54.08, p<0.001, r=0.77$. Concretely, winning invoked more feelings of pleasure $(M=7.36$ vs. $M=4.78)$ and dominance $(M=6.19$ vs. $M=3.67)$ than losing. Significant differences in arousal were absent for all conditions.

Table 1. Descriptive Statistics for Dependent Variables on All Experimental Conditions

\begin{tabular}{|c|c|c|c|c|}
\hline & \multicolumn{4}{|c|}{ Gender opponent } \\
\hline & \multicolumn{2}{|c|}{ Cross-gender competition } & \multicolumn{2}{|c|}{ Same gender competition } \\
\hline & Lost trial & Won trial & Lost trial & Won trial \\
\hline \multicolumn{5}{|l|}{ Pleasure } \\
\hline Mean $(S D)$ & $4.72(1.99)$ & $7.51(0.91)$ & $4.82(1.90)$ & $7.21(1.08)$ \\
\hline $\operatorname{Min} / \max$ & $1 / 8$ & $5 / 9$ & $1 / 8$ & $5 / 9$ \\
\hline \multicolumn{5}{|l|}{ Arousal } \\
\hline Mean $(S D)$ & $5.85(1.65)$ & $5.56(2.01)$ & $6.05(1.50)$ & $5.36(1.97)$ \\
\hline $\operatorname{Min} / \max$ & $2 / 9$ & $1 / 9$ & $3 / 9$ & $1 / 9$ \\
\hline \multicolumn{5}{|l|}{ Dominance } \\
\hline Mean $(S D)$ & $3.74(1.73)$ & $6.23(1.50)$ & $3.59(1.70)$ & $6.15(1.69)$ \\
\hline Min/max & $1 / 8$ & $2 / 9$ & $1 / 8$ & $2 / 9$ \\
\hline \multicolumn{5}{|l|}{ Frustration } \\
\hline Mean $(S D)$ & $4.85(2.54)$ & $1.87(1.84)$ & $4.43(2.62)$ & $1.90(1.74)$ \\
\hline Min/max & $0 / 10$ & $0 / 6$ & $0 / 9$ & $0 / 5$ \\
\hline \multicolumn{5}{|l|}{ Stress } \\
\hline Mean $(S D)$ & $5.15(2.63)$ & $3.51(2.73)$ & $4.13(2.71)$ & $3.31(2.83)$ \\
\hline $\operatorname{Min} / \max$ & $0 / 9$ & $0 / 9$ & $0 / 9$ & $0 / 9$ \\
\hline \multicolumn{5}{|l|}{ Challenge } \\
\hline Mean $(S D)$ & $5.60(1.63)$ & $4.65(1.57)$ & $5.35(1.44)$ & $4.58(1.60)$ \\
\hline $\operatorname{Min} / \max$ & $2.50 / 9$ & $1.75 / 9$ & $3 / 8.75$ & $1.75 / 9$ \\
\hline \multicolumn{5}{|c|}{ Perceived player skill } \\
\hline Mean $(S D)$ & $2.97(1.17)$ & $5.99(1.23)$ & $3.05(1.09)$ & $6.13(1.05)$ \\
\hline $\operatorname{Min} / \max$ & $1 / 7$ & $2.25 / 9$ & $1.50 / 6$ & $3.50 / 9$ \\
\hline \multicolumn{5}{|c|}{ Perceived opponent skill } \\
\hline Mean $(S D)$ & $8.23(1.04)$ & 5.85 (1.57) & $7.90(1.19)$ & $5.56(1.54)$ \\
\hline $\operatorname{Min} / \max$ & $6 / 10$ & $3 / 9$ & $6 / 10$ & $1 / 9$ \\
\hline
\end{tabular}


Table 2. Mixed ANOVA Results ( $F$ Values) for Gender Opponent, Group Competitiveness (Low vs. High), and Game Outcome (Losing vs. Winning)

\begin{tabular}{|c|c|c|c|c|c|c|c|c|}
\hline & \multicolumn{8}{|c|}{ Dependent variables } \\
\hline & Pleasure & Arousal & Dominance & Frustration & Stress & Challenge & $\begin{array}{c}\text { Perceived } \\
\text { skill }\end{array}$ & $\begin{array}{c}\text { Perceived } \\
\text { opponent } \\
\text { skill }\end{array}$ \\
\hline Gender opponent & 0.32 & 0.001 & 0.47 & 0.73 & $6.76 *$ & 1.39 & 0.78 & $5.02 *$ \\
\hline Game outcome & $71.33 * *$ & 3.14 & $54.08 * *$ & $108.12^{* *}$ & $22.62 * *$ & $13.67 * *$ & $398.47 * *$ & $109.32 * *$ \\
\hline Gender opponent $\times$ competitiveness & 0.09 & 1.14 & 0.06 & 0.73 & 1.55 & 0.05 & $4.52 *$ & $4.26 *$ \\
\hline Game outcome $\times$ competitiveness & 3.56 & 0.05 & 0.20 & 2.34 & 0.05 & 0.48 & 0.04 & 0.09 \\
\hline Gender opponent $\times$ outcome & 1.55 & 1.80 & 0.06 & 1.69 & 3.76 & 0.56 & 0.07 & 0.03 \\
\hline Three-way interaction & 1.55 & 0.22 & 0.01 & 1.01 & 0.01 & 1.33 & 0.52 & 2.64 \\
\hline
\end{tabular}

$* p<0.05 ; * * p<0.001$.

ANOVA, analysis of variance.

Perceived frustration and stress. Table 2 demonstrates a significant main effect of opponent gender on stress, $F(1$, $37)=6.76, p=0.01, r=0.15$, showing that participants perceived more stress when competing against male $(M=4.32)$ than female opponents $(M=3.69)$. There was also a main effect of game outcome, $F(1,37)=22.62, p<0.001, r=0.62$, indicating that players felt more stress when losing $(M=4.62)$ than when winning a contest $(M=3.39)$.

Moreover, ANOVA revealed a significant main effect of game outcome on frustration, $F(1,37)=108.12, p<0.001$, $r=0.86$. Players felt more frustrated when losing $(M=4.62)$ than when winning a game round $(M=1.88)$. No other significant differences were found in frustration levels.

Challenge. Our results revealed a significant main effect of outcome on perceived challenge, $F(1,37)=13.67, p<0.001$, $r=0.52$, showing that players experienced more challenge in losing $(M=5.48)$ than in winning conditions $(M=4.61)$.

Skill. For perceived skill, a significant main effect of game outcome was found, $F(1,37)=398.47, p<0.001$, $r=0.96$, suggesting that participants perceived their own skill as lower when losing $(M=3.01)$ compared to when winning $(M=6.06)$. However, there was a significant interaction between opponent gender and trait competitiveness, $F(1$, 37 ) $=4.52, p=0.04, r=0.33$ (see Fig. 2). Pairwise comparisons, using Fisher's least significant difference (LSD) test, revealed that low competitive women evaluated their skills significantly lower in cross-gender conditions than in same gender conditions $(p=0.04)$. However, when controlling for alpha inflation, a Tukey honestly significant different (HSD) follow-up test showed no significant differences between pairs. For perceived opponent skill, a significant main effect of outcome, $F(1,37)=109.32, p<0.001, r=0.86$, demonstrated that participants perceived the skills of opponents higher in losing conditions $(M=8.06)$ compared to winning conditions $(M=5.70)$. There was also a main effect of opponent gender, $F(1,37)=5.02, p=0.03, r=0.35$, showing that gaming skill of male competitors $(M=7.04)$ are perceived higher than those of female competitors $(M=6.72)$. However, results revealed a significant interaction between opponent gender and competitiveness trait, $F(1,37)=4.26$, $p=0.04, r=0.32$ (see Fig. 3). Post hoc comparisons indicated that low competitive women gave significantly higher ratings to male $(M=7$ vs. $M=6.39)$ than to female competitors (LSD test: $p<0.01$ vs. HSD test: $p=0.02$ ).

Objective measures. The ANOVA yielded a main effect of outcome on playing time, $F(1,36)=157.17, p<0.001$, $r=0.90$, showing a smaller duration for losing $(M=81.61$ seconds) than for winning conditions ( $M=128.87$ seconds). No other significant effects were found.

Furthermore, we subtracted AI's scores from player's scores, resulting in a total performance score of the crossgender and same gender condition. Given that we manipulated winning and losing, the variable outcome was excluded from the analysis. We therefore conducted a $2 \times 2$ (opponent gender: female vs. male $\times$ low vs. high competitive women) ANOVA, which revealed no significant effects. However, there was a marginally significant interaction between

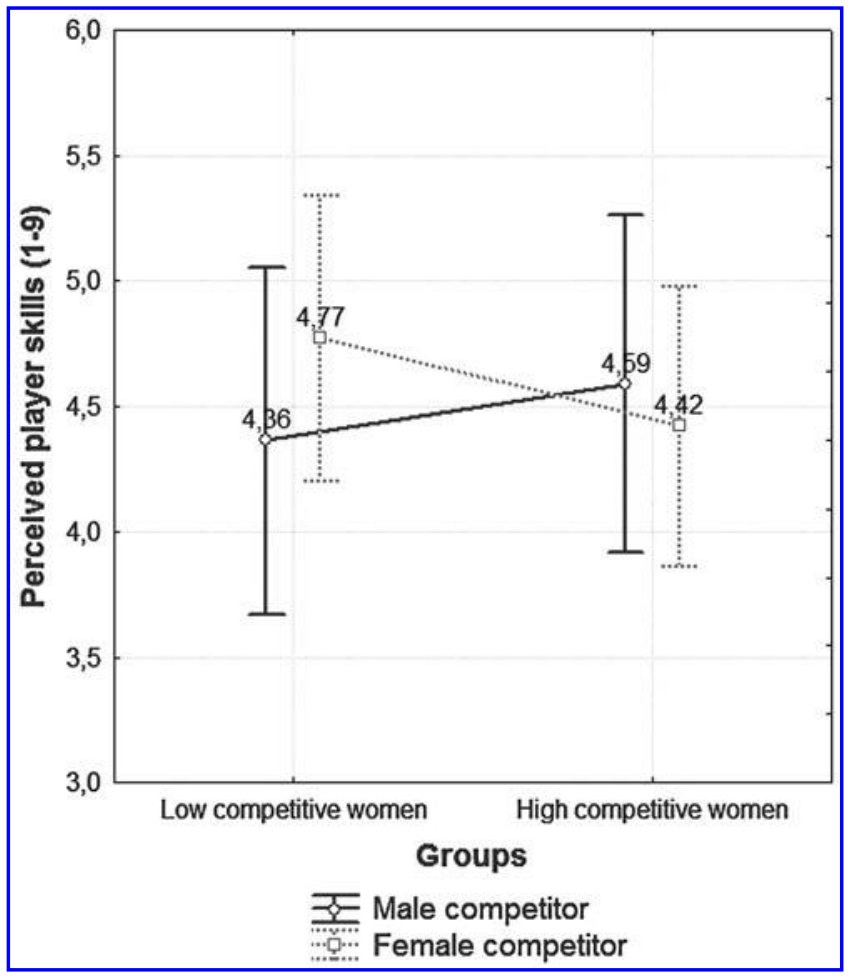

FIG. 2. Interaction between opponent gender and trait competitiveness on perceived player skill. 


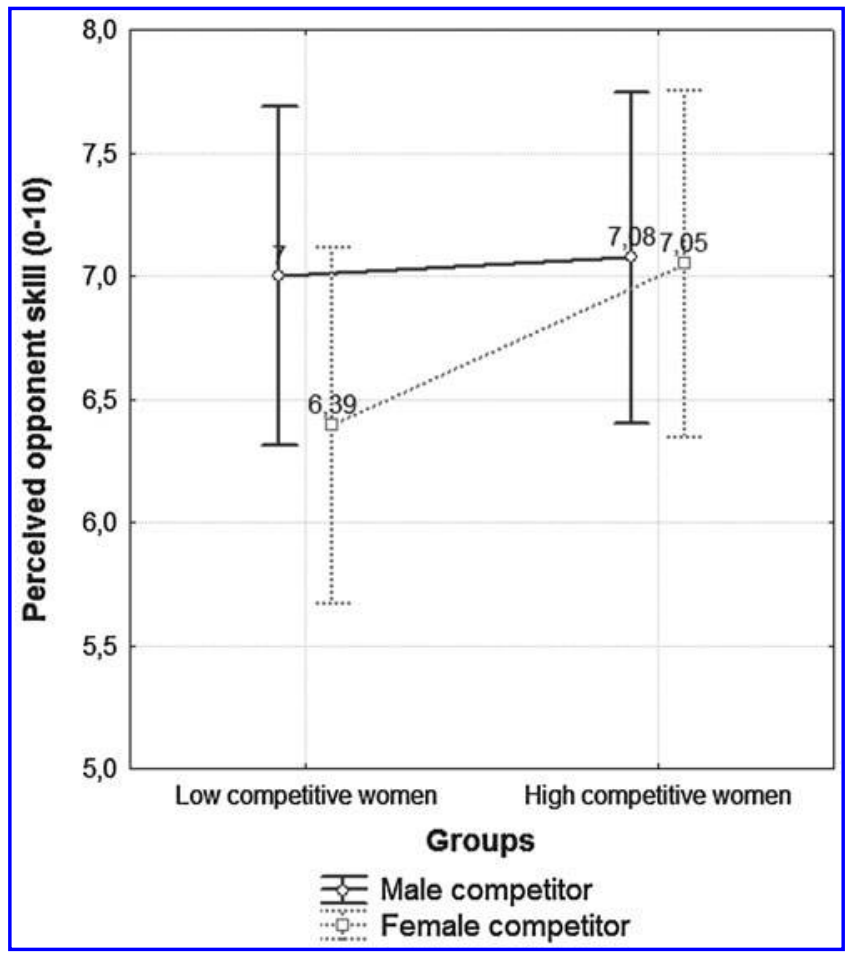

FIG. 3. Interaction between opponent gender and trait competitiveness on perceived opponent skill.

competitiveness and opponent gender, $F(1,36)=3.07$, $p=0.089, r=0.28$. Figure 4 depicts a reversed pattern in which low competitive women performed better in same gender conditions compared to high competitive women who scored better in cross-gender conditions.

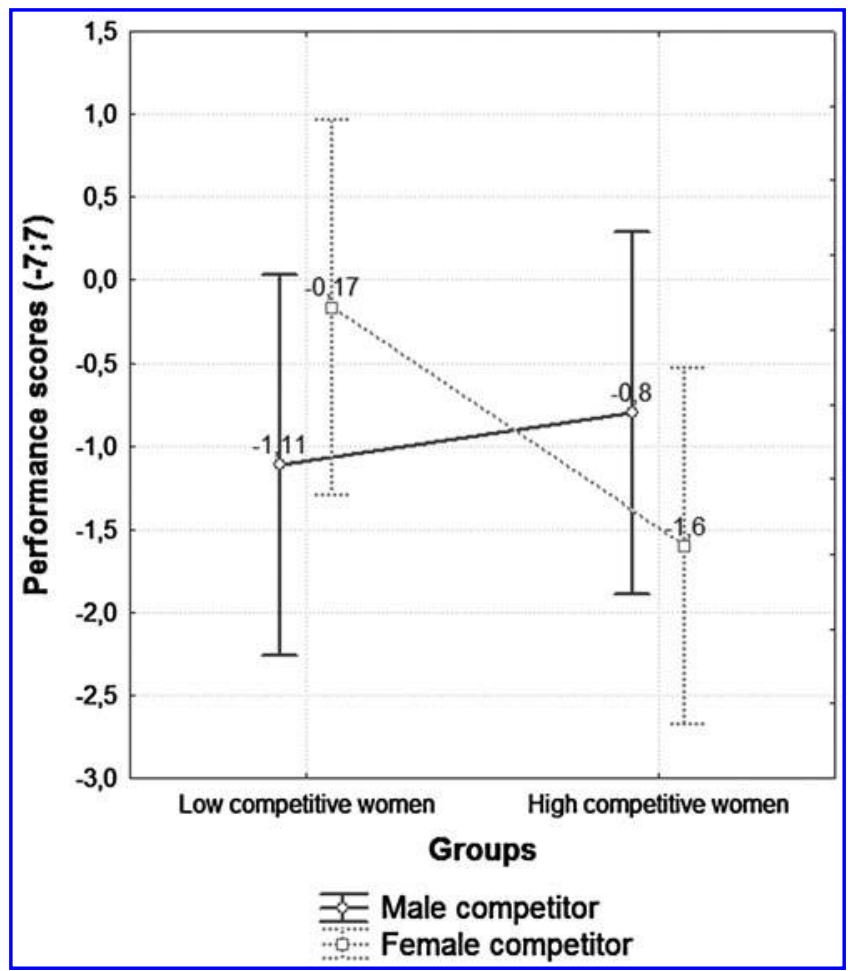

FIG. 4. Marginally significant interaction between opponent gender and trait competitiveness on performance scores.

\section{Discussion and Conclusion}

This study is one of the first to use an experimental approach to investigate how opponent gender affects the game experience of female players. In doing so, we looked at the effect of cross-gender competition versus same gender competition on player emotions and skill perceptions, when controlling for the game outcome (winning vs. losing). Although all variable scores (except for arousal) were dependent on game outcome, we were able to distinguish some distinctive opponent gender effects. Specifically, the present study provides novel evidence showing that perceived skill and stress level of (low competitive) female players are influenced by opponent gender in a gaming competition.

Hypothesis 1 stated that women would feel more challenged and perceive their gaming skills as lower in cross-gender competition. Whereas no effect was found for challenge, perceived player's skill was influenced by opponent gender and trait competitiveness. Specifically, we found that low competitive women rated their own skills lower in case of playing against men instead of women. Given that AI difficulty was equal in the cross-gender and same gender conditions, this finding suggests that low competitive women tend to assess their gaming skills incorrectly when playing against men. This result should be interpreted with caution, however, given that the effect was not significant when using a more conservative post hoc test, possibly due to the small sample size. Nonetheless, we found a similar pattern for perceived opponent skill. Besides a main effect of opponent gender, our analysis indicated an interaction between trait competitiveness and opponent gender. Low competitive women were found to perceive the skills of male competitors as higher than that of female competitors, which is in line with our previous finding. In other words, even when controlling for outcome, low competitive women seem to take gender as a criterion for gaming ability. These findings are in line with Bussey and Bandura's ${ }^{12}$ claim that gender dynamics diminish judgments about personal abilities within a gaming context. However, opponent's gender did not affect the judgments of high competitive women. This is not surprising, as more competitive people are less reluctant to enter tournaments ${ }^{45}$ and thus may be less prone to restrictive gender dynamics. While high competitive women may interpret gaming competition as a motivating challenge, low competitive women might perceive it as a threat affecting their sense of confidence. ${ }^{29}$

Hypothesis 2 stated that cross-gender competition would elicit more negative feelings in women. This was only partially supported, as opponent gender did not affect pleasure, dominance, or frustration. However, we did find that stress levels were influenced by opponent gender, indicating that participants felt more stress when playing against male than when playing against female competitors. This finding is not unexpected, as the literature has shown that stereotype threat can be a source of stress. ${ }^{57,58}$ When female players in cross-gender competition experience social identity threat, emotional strain can occur.

Additionally, we investigated the effect of opponent gender on objective game performance. Whereas there was a slight indication that low competitive women played better against female opponents than high competitive women, no notable differences were found in the players' performance. An explanation could be that the used objective measures were not sensitive enough for detecting differences in 
performance across the different conditions. Future research should therefore administer a more fine-grained method.

Another concern relates to ecological validity. Using a laboratory-based research method, the present study set up an artificial context in which participants were instructed to play a game against someone they did not know beforehand. Future studies should investigate cross-gender situations in more natural and/or different social gaming contexts. For instance, some online games offer the opportunity of hiding one's offline gender behind an avatar whose gender may or may not correspond with the player's gender. Further research could investigate whether women playing anonymously with male characters feel less threatened by their opponent. Moreover, there exists a whole spectrum of game genres affording different game playing strategies. ${ }^{59}$ Future studies could further examine female players' experiences in collaborative rather than competitive situations.

Despite these limitations, however, the present study provides novel insights into female game play and how this is affected by cross-gender competition. Not only do games as gender-linked tools hinder women to adopt gaming technology, 7,19 women also seem to "perform gender"60,61 during game play itself. Regardless of game outcome, they are likely to take their own and others' gender as a sign of gaming ability. Stereotype threat theory offers an explanation for this behavior, framing it as an artifact caused by the threat of confirming a negative stereotype as a self-characterization. ${ }^{29}$ In a broader sense, this threat can eventually lead women to disidentify with the playing field. ${ }^{62}$ Since games are a gateway to computer literacy, ${ }^{63}$ women are therefore placed in a disadvantaged position in today's information society. Providing insight into how gaming culture hinders female participation may therefore serve to understand gendered patterns of skill perception better in other fields such as the Internet and computer studies.

\section{Acknowledgments}

The authors would like to thank Evelien D'heer and Jan Decock for posing as confederates during the experiment. Special thanks go to GriN Multimedia for developing the Pong game.

\section{Author Disclosure Statement}

No competing financial interests exist.

\section{References}

1. Tobias S, Fletcher J. (2011) Computer games and instruction. Charlotte, NC: Information Age Publishing.

2. Bryce J, Rutter J. Gender dynamics and the social and spatial organization of computer gaming. Leisure Studies 2003; 22:1-15.

3. Terlecki M, Brown J, Harner-Steciw L, et al. Sex differences and similarities in video game experience, preferences, and self-efficacy: implications for the gaming industry. Current Psychology 2011; 30:22-33.

4. Willoughby T. A short-term longitudinal study of Internet and computer game use by adolescent boys and girls: prevalence, frequency of use, and psychosocial predictors. Developmental Psychology 2008; 44:195-204.

5. Greenberg BS, Sherry J, Lachlan K, et al. Orientations to video games among gender and age groups. Simulation \& Gaming 2010; 41:238-259.
6. Hartmann T, Klimmt C. Gender and computer games: exploring females' dislikes. Journal of Computer-Mediated Communication 2006; 11:910-931.

7. Behm-Morawitz E, Mastro D. The effects of the sexualization of female video game characters on gender stereotyping and female self-concept. Sex Roles 2009; 61:808-823.

8. Downs E, Smith SL. Keeping abreast of hypersexuality: a video game character content analysis. Sex Roles 2010; 62:721-733.

9. Bryce J, Rutter J, Sullivan C. (2006) Digital games and gender. In Rutter J, Bryce J, eds. Understanding digital games. London: Sage, pp. 185-204.

10. Jenson J, de Castell S, Fisher S. (2007) Girls playing games: rethinking stereotypes. In Proceedings of the 2007 Conference on Future Play. New York: ACM, pp. 9-16.

11. Bertozzi E. "You Play Like a Girl!" Cross-gender competition and the uneven playing field. Convergence: The International Journal of Research into New Media Technologies 2008; 14:473-487.

12. Bussey K, Bandura A. Social cognitive theory of gender development and differentiation. Psychological Review 1999; 106:676.

13. Bandura A. (1986) Social foundations of thought and action: $a$ social cognitive theory. Englewood Cliffs, NJ: Prentice-Hall.

14. Bandura A. Social cognitive theory of mass communication. Media Psychology 2001; 3:265-299.

15. Dickey MD. Girl gamers: the controversy of girl games and the relevance of female-oriented game design for instructional design. British Journal of Educational Technology 2006; 37:785-793.

16. Hayes E. Women, video gaming and learning: beyond stereotypes. TechTrends 2005; 49:23-28.

17. Kafai Y, Heeter C, Denner J, et al. (2008) Beyond Barbie and Mortal Kombat: new perspectives on gender and computer games. Cambridge, MA: MIT Press.

18. Sveningsson M. (2012) "Pity there's so few girls!" Attitudes to female participation in a Swedish gaming context. In Fromme J, Unger A, eds. Computer games and new media cultures. New York and London: Springer, pp. 425-441.

19. Carr D. Contexts, gaming pleasures, and gendered preferences. Simulation \& Gaming 2005; 36:464-482.

20. Laurel B. (2008) Notes from the utopian entrepreneur. In Kafai YB, Heeter C, Denner J, Sun JY, eds. Beyond Barbie and Mortal Kombat: new perspectives on gender and gaming. Cambridge, MA: MIT Press, pp. 21-32.

21. Lin H. (2008) Body, space and gendered gaming experiences: a cultural geography of homes, cybercafes and dormitories. In Kafai YB, Heeter C, Denner J, Sun JY, eds. Beyond Barbie and Mortal Kombat: new perspectives on gender and gaming. Cambridge, MA: MIT Press, pp. 67-81.

22. Lucas K, Sherry JL. Sex differences in video game play: a communication-based explanation. Communication Research 2004; 31:499-523.

23. Schott GR, Horrell KR. Girl gamers and their relationship with the gaming culture. Convergence: The International Journal of Research into New Media Technologies 2000; 6:36-53.

24. Yee N. (2008) Maps of digital desires: exploring the topography of gender and play in online games. In Kafai YB, Heeter C, Denner J, Sun JY, eds. Beyond Barbie and Mortal Kombat: new perspectives on gender and gaming. Cambridge, MA: MIT Press, pp. 83-96.

25. Gneezy U, Niederle M, Rustichini A. Performance in competitive environments: gender differences. The Quarterly Journal of Economics 2003; 118:1049-1074. 
26. Niederle M, Vesterlund L. Gender differences in competition. Negotiation Journal 2008; 24:447-463.

27. Eastin MS. Video game violence and the female game player: self- and opponent gender effects on presence and aggressive thoughts. Human Communication Research 2006; 32:351-372.

28. LaRose R. (2009) Social cognitive theories of media selection. In Hartmann T, ed. Media choice: a theoretical and empirical overview. New York: Routledge, pp. 10-31.

29. Steele CM, Aronson J. Stereotype threat and the intellectual test performance of African Americans. Journal of Personality \& Social Psychology 1995; 69:797-811.

30. Cadinu M, Maass A, Frigerio S, et al. Stereotype threat: the effect of expectancy on performance. European Journal of Social Psychology 2003; 33:267-285.

31. Spencer SJ, Steele CM, Quinn DM. Stereotype threat and women's math performance. Journal of Experimental Social Psychology 1999; 35:4-28.

32. Stangor C, Carr C, Kiang L. Activating stereotypes undermines task performance expectations. Journal of Personality \& Social Psychology 1998; 75:1191.

33. Lee J-ER. To reveal or to cloak? Effects of identity salience on stereotype threat responses in avatar-represented group contexts. International Journal of Internet Science 2009; 4:34-49.

34. Günther C, Ekinci NA, Schwieren C, et al. Women can't jump?-An experiment on competitive attitudes and stereotype threat. Journal of Economic Behavior \& Organization 2010; 75:395-401.

35. Lee J-ER, Nass C. Distinctiveness-based stereotype threat and the moderating role of coaction contexts. Journal of Experimental Social Psychology 2012; 48:192-199.

36. Castell S, Jenson J. Her own boss: gender and the pursuit of incompetent play. In Proceedings of DiGRA 2005 Conference: Changing Views-Worlds in Play. Vancouver, Canada.

37. Gyongran J. Women in digital games and their meaning in gaming culture: in-depth interviews with high-level female gamers. Korea Journalism Review 2008; 2:107-127.

38. Ben-Zeev T, Fein S, Inzlicht M. Arousal and stereotype threat. Journal of Experimental Social Psychology 2005; 41:174-181.

39. Vick SB, Seery MD, Blascovich J, et al. The effect of gender stereotype activation on challenge and threat motivational states. Journal of Experimental Social Psychology 2008; 44:624-630.

40. Keller J, Dauenheimer D. Stereotype threat in the classroom: dejection mediates the disrupting threat effect on women's math performance. Personality \& Social Psychology Bulletin 2003; 29:371-381.

41. Cadinu M, Maass A, Rosabianca A, et al. Why do women underperform under stereotype threat? Evidence for the role of negative thinking. Psychological Science 2005; 16:572-578.

42. Frijda NH, Kuipers P, Ter Schure E. Relations among emotion, appraisal, and emotional action readiness. Journal of Personality \& Social Psychology 1989; 57:212.

43. Poels K, Hoogen Wvd, Ijsselsteijn W, et al. Pleasure to play, arousal to stay: the effect of player emotions on digital game preferences and playing time. CyberPsychology, Behavior, \& Social Networking 2012; 15:1-6.

44. Ravaja N. The psychophysiology of digital gaming: the effect of a non co-located opponent. Media Psychology 2009; 12:268-294.

45. Vorderer P, Hartmann T, Klimmt C. (2003) Explaining the enjoyment of playing video games: the role of competition. In Proceedings of the Second International Conference on
Entertainment Computing. Pittsburgh, PA: Carnegie Mellon University, pp. 1-9.

46. Johnson JL. A mediated-moderation model of stereotype threat and performance pressure effects. Doctoral dissertation, Auburn University, 2012.

47. Dunn JG, Dunn JC. Relationships among the Sport Competition Anxiety Test, the Sport Anxiety Scale, and the Collegiate Hockey Worry Scale. Journal of Applied Sport Psychology 2001; 13:411-429.

48. Martens R, Vealey RS, Burton D. (1990) Competitive anxiety in sport. Champaign, IL: Human Kinetics Publishers.

49. Martin JJ, Gill DL. The relationships among competitive orientation, sport-confidence, self-efficacy, anxiety, and performance. Journal of Sport \& Exercise Psychology 1991; 13:149-159.

50. Houston J, Harris P, McIntire S, et al. Revising the Competitiveness Index using factor analysis. Psychological Reports 2002; 90:31-34.

51. Lang PJ. (1980) Behavioral treatment and bio-behavioral assessment: computer applications. In Sidowski J, Johnson J, Williams T, eds. Technology in mental health care delivery systems. Norwood, NJ: Ablex Publishing, pp. 119-137.

52. Bradley MM, Lang PJ. Measuring emotion: the self-assessment manikin and the semantic differential. Journal of Behavior Therapy \& Experimental Psychiatry 1994; 25:49-59.

53. Mastro DE, Eastin MS, Tamborini R. Internet search behaviors and mood alterations: a selective exposure approach. Media Psychology 2002; 4:157-172.

54. Novak TP, Hoffman DL, Yung Y-F. Measuring the customer experience in online environments: a structural modeling approach. Marketing Science 2000; 19:22-42.

55. Atari. Pong [Arcade game]. Atari Inc., 1972.

56. Brown RM, Hall LR, Holtzer R, et al. Gender and video game performance. Sex Roles 1997; 36:793-812.

57. Inzlicht M, Kang SK. Stereotype threat spillover: how coping with threats to social identity affects aggression, eating, decision making, and attention. Journal of Personality \& Social Psychology 2010; 99:467.

58. Schmader T, Johns M, Forbes C. An integrated process model of stereotype threat effects on performance. Psychological Review 2008; 115:336.

59. Kaye LK, Bryce J. Putting the "fun factor" into gaming: the influence of social contexts on experiences of playing videogames. International Journal of Internet Science 2012; 7:23-36.

60. West C, Zimmerman DH. Doing gender. Gender \& Society 1987; 1:125-151.

61. West C, Fenstermaker S. Doing difference. Gender \& Society $1995 ; 9: 8-37$.

62. Steele CM. A threat in the air: how stereotypes shape intellectual identity and performance. American Psychologist 1997; 52:613.

63. Cooper J. The digital divide: the special case of gender. Journal of Computer Assisted Learning 2006; 22:320-334.

Address correspondence to: Lotte Vermeulen

Department of Communication Sciences iMinds-MICT-Ghent University Korte Meer 7-9-11 9000 Ghent Belgium

E-mail: lotte.vermeulen@ugent.be 